\title{
Age of onset of a normally timed pubertal growth spurt affects the final height of children
}

\author{
Yehuda Limony', Sławomir Kozieł ${ }^{2}$ and Michael Friger ${ }^{3}$
}

\begin{abstract}
BACKGROUND:The exact nature of the relationship between the age of onset of puberty and final height in normally maturing children is controversial. Some authors have claimed that the age of pubertal onset does not affect final height, and others have claimed the opposite. We hypothesized that both height and the age of onset of the pubertal growth spurt (PGS) are correlated to final height.
\end{abstract}

METHODS: The height measurements of 335 children (162 girls) were analyzed in an observational retrospective study. The age and height at the onset of the PGS were computed from the equations of the Karlberg's infancy-childhood-puberty model.

RESULTS: A very low correlation was found between the age of onset of the PGS and final height. However, the correlation became very high when the parameter "height at onset of the PGS" was included in the regression analysis. The model was found reliable when tested on growth data of 60 Israeli children.

CONCLUSIONS: Final height is influenced by both height and the age of onset of the PGS in normal maturing children. A normal but early puberty exerts a negative effect on final height. A delayed PGS exerts a positive effect on final height.

$P$ ediatricians and pediatric endocrinologists are well aware that precocious puberty exerts a negative influence on statural growth and final height. However, the exact nature of the relationship between the age of onset of puberty, statural growth, and final height in normally maturing children is controversial. Some authors have claimed that age of pubertal onset does not affect final height (Marshall and Tanner (1), Vizmanos et al. (2)), and others have claimed the opposite (Bourguignon (3), Karlberg (4), and Tanaka (5)).

It is against this background that we hypothesized that both height and the age of onset of the pubertal growth spurt (PGS) are correlated to final height. Since the pattern of statural growth in childhood is nonlinear, we also hypothesized that a nonlinear equation would be more appropriate than a linear equation to describe the influence of age and height at the age of onset of the PGS on final height. Hence, the purpose of our study was to test the hypothesis that final height correlates to both age and height at the onset of the PGS and to mathematically describe this correlation. This report informs on the results of our testing of these hypotheses and provides a mathematical description of the relationship between final height and the age and height at the onset of the PGS.

\section{RESULTS}

The mean age of the onset of the PGS for boys was $11.9 \mathrm{y} \pm 1.1$ (SD) and $10.0 \pm 0.7 \mathrm{y}$ for girls. Specifically, the age of onset of the PGS was between (i) 8.5 and 9.4 y in 2 boys, (ii) 9.5 and $10.4 \mathrm{y}$ in 16 boys, (iii) 10.5 and $11.4 \mathrm{y}$ in 48 boys, (iv) 11.5 and 12.4 y in 60 boys, (v) 12.5 and 13.4 y in 33 boys, (vi) 13.5 and 14.4 y in 16 boys, and (vii) 14.5 and 15.5 y in 3 boys. For girls, the age of onset of the PGS was between (i) 7.5 and 8.4 $\mathrm{y}$ in 2 girls, (ii) 8.5 and $9.4 \mathrm{y}$ in 47 girls, (iii) 9.5 and $10.4 \mathrm{y}$ in 71 girls, (iv) 10.5 and 11.4 y in 43 girls, and (v) 11.5 and 12.4 $\mathrm{y}$ in 5 girls. Groups (i) and (vii) in the boys and groups (i) and (v) in the girls were omitted from the analyses because their sample size was very small. The mean height $( \pm S D)$ at the onset of the PGS for boys was $143.9 \pm 6.5$ and $132.2 \pm 5.1 \mathrm{~cm}$ for girls. The mean final height $( \pm \mathrm{SD})$ of the boys was $174.2 \pm 6.3$ and $159.7 \pm 5.8 \mathrm{~cm}$ for the girls. The height gain during the PGS was then determined from the difference between the final height and the height at the onset of PGS. We found that the average height gain during the PGS is $30.3 \mathrm{~cm}$ for boys and $27.5 \mathrm{~cm}$ for girls and that these height gains are expected in normally growing boys and girls $(4,6)$. The final height measurements, when expressed either in centimeters or as standard deviation scores (SDS), were normally distributed.

The results of the linear regression analysis revealed that the correlation between the final height and the age of the onset of the PGS was very low for both boys $(r=0.04)$ and girls $(r=0.05)$. When the parameter "height at onset of the PGS" was included in the regression analysis, the correlation between final height and both the age of onset of the PGS and height at the onset of the PGS became very high $(r=0.9)$. The correlation was always high regardless of whether these parameters were expressed in centimeters $(\mathrm{cm})$ or as SDS. When a third parameter "age of onset of PGS squared" was included in the analysis, the resultant correlation did not change significantly

'Pediatric Endocrinology Unit, Faculty of Health Sciences, Ben-Gurion University of the Negev, Be'er-Sheva, Israel; ${ }^{2}$ Institute of Anthropology, Polish Academy of Sciences, Wroclaw, Poland; ${ }^{3}$ Department of Public Health, Faculty of Health Sciences, Ben-Gurion University of the Negev, Be'er-Sheva, Israel. Correspondence: Yehuda Limony (limony@zahav.net.il) 
Table 1. Results of the linear regression analysis with two independent variables-boys

\begin{tabular}{|c|c|c|c|c|c|}
\hline Variable & $\begin{array}{l}\text { Regression } \\
\text { coefficient }\end{array}$ & $\begin{array}{l}\text { SE of the regression } \\
\text { coefficient }\end{array}$ & Beta $^{a}$ & $P$ value & $\begin{array}{l}\text { Confidence interval of the } \\
\text { regression coefficient (95\%) }\end{array}$ \\
\hline Intercept & $58.28(-4.00)$ & $4.62(0.33)$ & $0.00(0.00)$ & $<0.001(<0.001)$ & $49.16-67.41(-4.66$ to -3.35$)$ \\
\hline $\begin{array}{l}\text { Height at the onset of the } \\
\text { pubertal growth spurt }\end{array}$ & $0.95(0.93)$ & $0.03(0.03)$ & $0.97(0.97)$ & $<0.001(<0.001)$ & $0.88-1.02(0.87-0.99)$ \\
\hline
\end{tabular}

Final height of the boys is the dependent variable, and age of onset of puberty and height at the onset of puberty are the independent variables. The analysis was made when the final height and height at the onset of the pubertal growth spurt are expressed in centimeters or as a standard deviation score (parentheses). Adjusted $r^{2}=0.82$ ( 0.85 ).

astandardized coefficient.

Table 2. Results of the linear regression analysis with three independent variables_-boys

\begin{tabular}{|c|c|c|c|c|c|}
\hline Variable & $\begin{array}{l}\text { Regression } \\
\text { coefficient }\end{array}$ & $\begin{array}{l}\text { SE of the regression } \\
\text { coefficient }\end{array}$ & Beta $^{a}$ & $P$ value & $\begin{array}{l}\text { Confidence interval of the } \\
\text { regression coefficient (95\%) }\end{array}$ \\
\hline Intercept & $25.24(-15.77)$ & $20.76(2.90)$ & $0.00(0.00)$ & $<0.08(<0.001)$ & -15.75 to 66.23 ( -21.50 to -10.04$)$ \\
\hline $\begin{array}{l}\text { Age of onset of the } \\
\text { pubertal growth spurt } \\
\text { squared }\end{array}$ & $-0.23(-0.08)$ & $0.14(0.02)$ & $-1.00(-2.21)$ & $<0.05(<0.001)$ & -0.51 to $0.05(-0.12$ to -0.04$)$ \\
\hline
\end{tabular}

Final height of the boys is the dependent variable, and the age of onset of puberty, the age of the onset of puberty squared, and the height at the onset of puberty are the independent variables. The analysis was made when the final height and the height at onset of the pubertal growth spurt are expressed in centimeters or as a standard deviation score (parentheses). Adjusted $r^{2}=0.82(0.86)$.

astandardized coefficient.

Table 3. Results of the linear regression analysis with two independent variables—girls

\begin{tabular}{|c|c|c|c|c|c|}
\hline Variable & $\begin{array}{l}\text { Regression } \\
\text { coefficient }\end{array}$ & $\begin{array}{c}\text { SE of the regression } \\
\text { coefficient }\end{array}$ & Beta $^{a}$ & $P$ value & $\begin{array}{l}\text { Confidence interval of the } \\
\text { regression coefficient (95\%) }\end{array}$ \\
\hline Intercept & $26.55(-5.77)$ & $5.34(0.41)$ & $0.00(0.00)$ & $<0.001(<0.001)$ & $15.9-37.2(-6.60$ to -4.95$)$ \\
\hline $\begin{array}{l}\text { Height at the onset of the } \\
\text { pubertal growth spurt }\end{array}$ & $1.09(0.98)$ & $0.04(0.03)$ & $0.92(1.00)$ & $<0.001(<0.001)$ & $1.00-1.16(0.92-1.05)$ \\
\hline
\end{tabular}

Final height of the girls is the dependent variable, and age of onset of puberty and height at the onset of puberty are the independent variables. The analysis was made when the final height and height at the onset of the pubertal growth spurt are expressed in centimeters or as a standard deviation score (parentheses). Adjusted $r^{2}=0.82(0.85)$.

astandardized coefficient.

(Tables 1-4). Finally, none of the correlations significantly changed when the BMI was included in the analyses.

According to the results of the regression analysis, the impact of age is greater in children whose PGS occurs early than in those children whose PGS is delayed. In children who have the same height SDS at the onset of their PGS, the absolute loss in the final height of an early maturing child is greater than the absolute gain in final height of a late maturing child for both girls (Figure 1) and boys (Figure 2). Summaries of all the regression analyses are presented for boys in Tables 1 and 2 and for girls in Tables 3 and 4, respectively. Specifically, boys whose PGS occurs 1 y earlier than the average age of onset of the PGS (age 11.9 y) have an estimated adult height that is shorter by 0.47 SDS or $2.9 \mathrm{~cm}$. Boys whose PGS occurs 2 y earlier than average have an estimated adult height that is shorter by 1.1 SDS or $6.8 \mathrm{~cm}$. Boys whose PGS occurs 1 y later than the average age of onset of the PGS have an estimated adult height which is taller by 0.31 SDS or $1.9 \mathrm{~cm}$. Boys whose PGS occurs 2 y later than the average age of onset have an estimated adult height which is taller by 0.46 SDS or $2.86 \mathrm{~cm}$. Girls whose PGS occurs 1 y earlier than the average age of onset of the PGS (age $10 \mathrm{y}$ ) have an estimated adult height that is shorter by 0.76 SDS or $4.6 \mathrm{~cm}$. Girls whose PGS occurs 2 y earlier than the average age of onset of the PGS have an estimated adult height that is shorter by 1.8 SDS or $10.8 \mathrm{~cm}$. Girls whose PGS occurs 1 y later than the average age of onset of the PGS have an estimated adult height which is taller by 0.48 SDS or $2.9 \mathrm{~cm}$. Girls whose PGS occurs 2 y later than the average age of onset of the PGS have an estimated adult height which is taller by $0.5 \mathrm{SDS}$ or $3 \mathrm{~cm}$.

In order to validate our model in contemporary children, we used height data of Israeli children who were followed up to final height in a growth clinic during the period 2004-2013. 
Table 4. Results of the linear regression analysis with three independent variables — girls

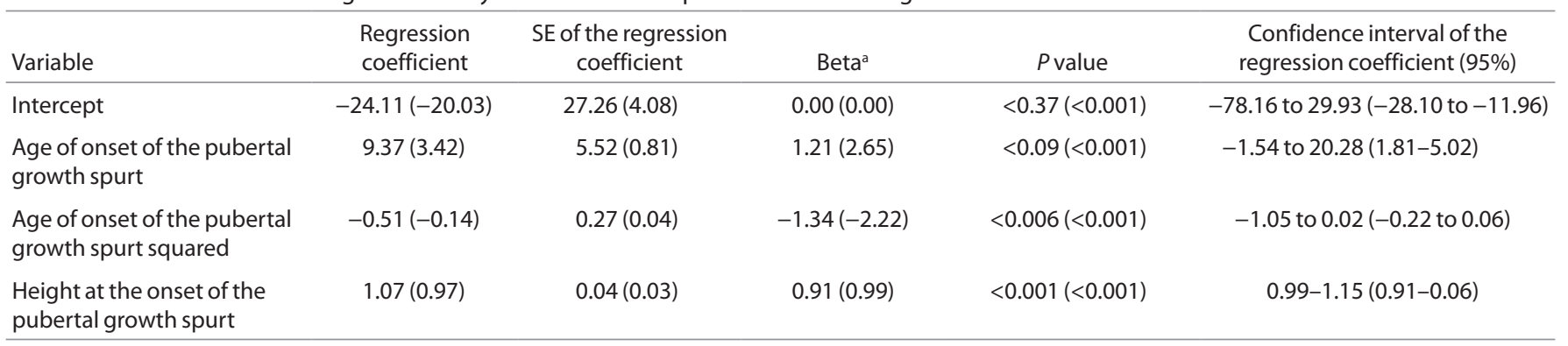

Final height of the girls is the dependent variable, and age of the onset of puberty, age of onset of puberty squared, and height at the onset of puberty are the independent variables. The analysis was made when the final height and height at the onset of the pubertal growth spurt are expressed in centimeters and as a standard deviation score (parentheses). Adjusted $r^{2}=0.83(0.86)$.

astandardized coefficient.

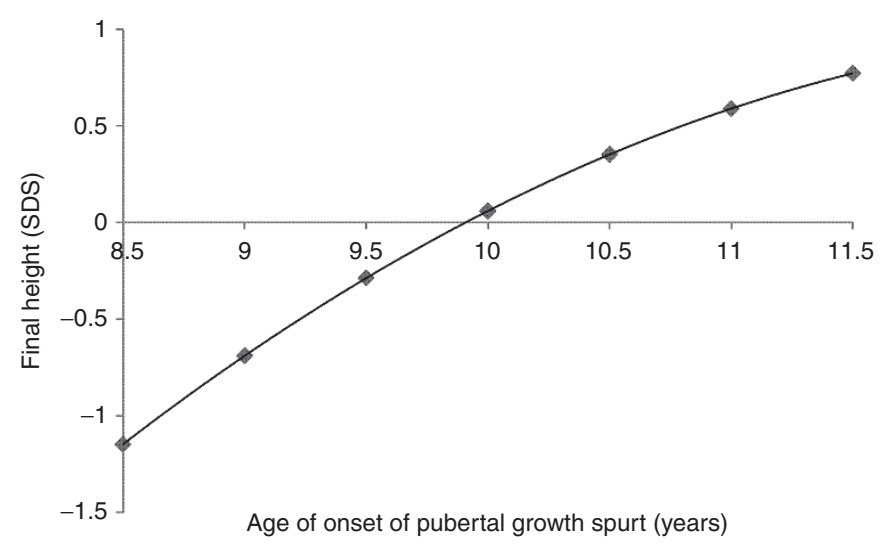

Figure 1. An example of the relationship between final height and the age of onset of the pubertal growth spurt in girls with median height. This graph was generated using the regression coefficients that are displayed in Table 4 and assumes that height-standard deviation score (SDS) at the onset of the pubertal growth spurt is zero. From this figure, it is evident that for girls who are growing along the same height-SDS, the final height of girls in whom the onset of the PGS occurs early is lower than those in whom the onset of the PGS occurs late. The change (gain or loss) in final height is more pronounced at young ages. For example, when onset of the PGS occurs when the girl is $8.5 \mathrm{y}$ old instead of $10 \mathrm{y}$ old, this girl "loses" about 1.2 SDS in final height. When age of onset of the PGS occurs late, for example, when the girl is $11.5 \mathrm{y}$ old instead of $10 \mathrm{y}$ old, the "gain" is only 0.67 SDS in final height. 1 SDS at age $20 \mathrm{y}=6.02 \mathrm{~cm}$ according to Karlberg's infancy-childhood-puberty model (15).

This group consisted of 60 healthy children (34 boys and 26 girls) who were referred to the growth clinic for investigation of their short stature. None of the referred children had a pathological condition that caused their short stature.

The mean error of prediction of the second-degree polynomial equation, which was defined as the difference between the predicted and observed heights, was 0.24 SDS $(1.4 \mathrm{~cm})(95 \%$ confidence interval: -0.56 to +1.04 SDS) in the girls and 0.45 SDS $(2.8 \mathrm{~cm})$ (95\% confidence interval: -0.21 to +1.11 SDS) in the boys. Since we considered that these errors are nonsignificant, these results indicate that the model is also valid for contemporary (Israeli) children.

\section{DISCUSSION}

In this report, we mathematically describe the relationship between the age and height at the onset of the PGS and final

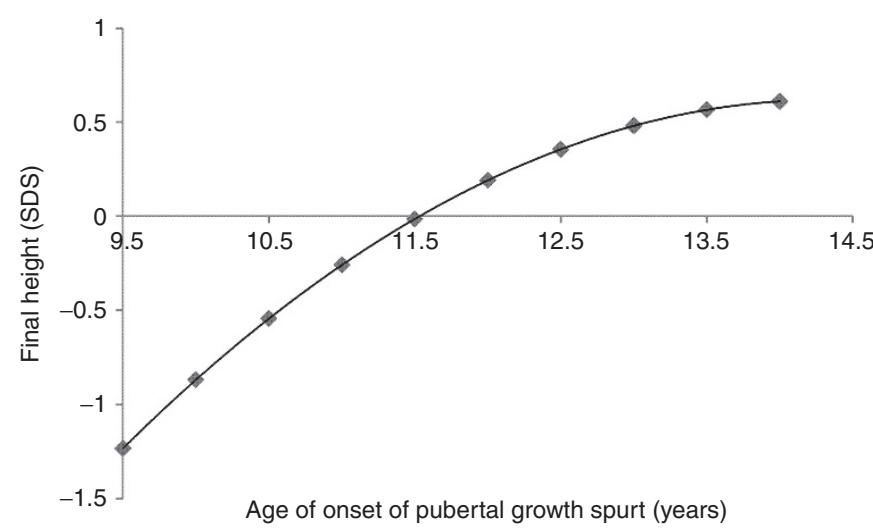

Figure 2. An example of the relationship between final height and age of the onset of the pubertal growth spurt in boys with median height. This graph was generated using the regression coefficients that are displayed in Table 2 and assumes that height-standard deviation score (SDS) at the onset of the pubertal growth spurt is zero. 1 SDS at age $20 \mathrm{y}=6.23 \mathrm{~cm}$ according to Karlberg's infancy-childhood-puberty model (15).

height of normally maturing children. According to this description, the final height SDS is shorter than the onset height SDS for a PGS that starts early, and this "loss" of height SDS becomes very significant when the age of onset of the PGS occurs very early. The possibility of a final short stature in children with a precocious puberty is usually a source of great concern to children and their parents as well as clinicians. Our results suggest that a short adult stature is possible not only in children with precocious puberty but also to a lesser extent in normal children in whom puberty begins at the early end of the normal spectrum of pubertal onset.

The relationship between final height and age and height at onset of the PGS was analyzed in this study by two modes: one with two independent variables and the second with a third variable - "age at onset of the PGS squared." Although adding the parameter "age at onset of the PGS squared" in the regression analyses did not substantially change the correlation coefficient, the resultant curve does change from a linear curve to nonlinear polynomial curve. Hence, each regression analysis accurately describes the dependence of the final height on the age and height at the onset of the PGS. However, the polynomial model is compatible with the one that has been reported 
by others in previous publications in which the authors gave no mathematical description of the curve. It is impossible to conclude from our study which model best describes this dependence in reality, and more studies in other populations are necessary in order to answer this question. Since the difference between the linear and polynomial curves is greater at their extremes, it is expected that analyzing the PGS of children who have precocious or extremely delayed puberty might possibly clarify this issue.

The duration of the PGS is described in the literature as a parameter that may influence final height. In this study, we found a high linear correlation between the parameters "age at onset of the PGS" and "the duration of the PGS" in the boys $(r=-0.84)$ and in the girls $(r=-0.88)$. Since the inclusion of both parameters in the regression analysis creates a problem of colinearity, only "the age at onset of the PGS" was included in the analysis.

We have no data on the secondary sexual changes (Tanner stages) of the children who participated in the Wroclaw Growth Study. Accordingly, we could not determine whether the duration of puberty (from Tanner stage 2 to 5 ) influences final height. However, readers should be aware that a wide variability can exist between the Tanner stages of puberty and indices of pubertal growth, such as age and height at the onset of the PGS and the age and height at peak height velocity (PHV) and final height. In their study of boys and girls in the Harpenden Growth Study, Tanner et al. (7) found that the correlation coefficient between Tanner stage 2 (onset of puberty) and the age at onset of the PGS was 0.72 in girls and 0.39 in boys and between the age at PHV was 0.78 in girls and 0.47 in boys. It is clear from these correlation coefficients that clinical signs of puberty are much less accurate predictors of final height than auxological parameters.

Unlike other clinical signs of puberty, the menarche correlates better with the PGS $(r=0.77)$ and appears $1.1 \mathrm{y}$ after the age at PHV (8). A positive relationship between age at menarche and adult height $(9,10)$ have been demonstrated in several studies, but the correlation found was low and only $1 \%$ of the variation in height was explained by the variation in age at menarche. In view of our findings, it is possible that this low correlation is the result of exclusion of the parameter height at age of menarche in the regression analysis of these studies.

In this study, we examined the growth data of children whose puberty occurred between 1961 and 1972. Contemporary children are more obese, and the results of several studies have found that BMI exerts a negative effect on the height gain during puberty $(11,12)$. We found no evidence of this relationship after analyzing our data, and we attribute this finding to the very small number of obese children in the study population: only five boys and four girls had a BMI above the 90th percentile. More studies are necessary in order to check whether the reduction of height gain of the PGS of obese children that was found in those studies is due solely to an earlier PGS (as predicted by our model) or by a direct effect on the duration of the PGS that may affect its height gain.

In view of our novel findings on the determinants of final height, we suggest that more investigations should be undertaken in order to confirm our results in other populations of children.

In conclusion, we characterized the relationship between both age and height at the onset of the PGS and final height using published data of a study population of growing children. We found that this relationship can be described by either a linear equation or a nonlinear second-degree polynomial. Both equations are consistent with the observations that not only precocious puberty but also an early puberty that occurs within the normal limits exerts a significantly negative effect on final height. It is also evident from the equations that the magnitude of the effect of the PGS on final height is dependent upon the age of onset of the PGS: when the onset of the PGS occurs early, the negative effect of the PGS on final height is great. Both are also consistent with the observations that the effect of delayed puberty on the final height is modest in boys. This effect is more discernible when the second-degree polynomial is used to describe the relationship. Accordingly, we conclude that the second-degree polynomial is better than the linear equation to describe the relationship between both age and height at the onset of the PGS and final height. Finally, our findings may have practical implications for clinicians and pediatricians who medically manage the final height of growing children as they pass through puberty.

\section{METHODS}

The study population are children who participated in the longitudinal Wroclaw Growth Study that was conducted over 11 y from 1961 until 1972 (refs. 13,14). The Wroclaw Growth Study was approved by the Polish Academy of Sciences and comprised first-grade boys and girls from nine randomly selected Wroclaw elementary schools. Information on details of the study was provided to parents. A parent or both parents voluntarily came to the Institute of Anthropology with the child for examination in April/May 1961, and then at annual intervals. Institute staff notified parents before each examination. Parental participation in the examinations was accepted as implicit informed consent. Polish law at the time of the study did not require written consent of parents for children to participate in growthrelated studies. Participation in the project was not mandatory, and children were free to withdraw at any time.

At the start of the study, 860 children ( 425 boys) whose average age was 7.9 y (boys: 8.0 (mean) $\pm 0.3(\mathrm{SD})$; girls; $7.9 \pm 0.3$ ) and residents of Wroclaw, Poland, were recruited and then examined annually in April-May for the next $11 \mathrm{y}$. Four hundred and eight children (196 boys; $18.3 \pm 1.0$ y; 212 girls; $17.3 \pm 0.8$ y) completed the study. Although 452 children did not complete the study, at least eight measurements were made on each participant. The heights and weights of the participants who completed the study were not significantly different from those who dropped out of the study. We tested our hypotheses using the data from 335 participants (162 girls) who completed the Wroclaw Growth Study.

The age of the PHV, the age of onset of the PGS, and the height at the onset of the PGS were computed for every child using Karlberg's infancy-childhood-puberty (ICP) model (15). Height at the onset of the PGS and final height were also expressed as SDS using the ICP model. We defined "end of the PGS" as the 1-y period after the occurrence of PHV when the height growth velocity is reduced to less than $0.5 \mathrm{~cm} / \mathrm{y}$. We defined "final height" as the last height measurement that was made at the end of the PGS. A computer program, which was developed by one of the authors (Y.L.), was used for curve fitting. The program automatically fitted the ICP model to the individual height records of every child and generated the age at PHV and the age of onset of the PGS for each child. Goodness of fit was high as evidenced by the pooled residual variance: $2.26 \mathrm{~cm}^{2}$ (boys) and $1.48 \mathrm{~cm}^{2}$ (girls). 
This procedure was done because determining the peak of the PGS by calculating the growth velocity between two height measurements that were made annually can lead to inaccurate results. Growth during the PGS is described by the ICP model as a logistic function with the age at PHV as one of its parameters. Any change in this parameter changes the function's shape. The value of the age at PHV in the bestfitting curve of the child's measurements was the value that was used by the computer in the analysis. Accordingly, this analytical method which relies on all of the child's height measurements is more accurate than the analytical method which relies on only two height measurements. According to the ICP model, the age at onset of the PGS appears $2 \mathrm{y}$ before the age at PHV and is the first change in height that is greater than 0.3 SDS in the prepubertal period. We considered both these criteria when determining the age at onset of the PGS. Height at the onset of the PGS was calculated by the same program using a nonlinear ICP-based interpolation between two adjacent measurements (before and after) of the age of onset of the PGS. The correlations between the final heights and the (i) heights at the onset of the PGS, (ii) ages at the onset of the PGS, and (iii) ages of onset of the PGS squared were calculated using a multiple regression analysis. All data were analyzed using a computerized statistical software program (SPSS version 17.0 for Windows; SPSS, Chicago, IL).

\section{ACKNOWLEDGMENTS}

The authors thank Arieh Bomzon, ConsulWrite (http://www.consulwrite. com), for his editorial assistance in preparing the manuscript.

\section{STATEMENT OF FINANCIAL SUPPORT}

The authors declare that no financial assistance was received for this investigation.

Disclosure: The authors declare that there are no conflicts of interest with any financial organization or manufacturer on the manuscript's content.

\section{REFERENCES}

1. Marshall WA, Tanner JM. Puberty. In: Falkner F, Tanner JM, eds. Human Growth: A Comprehensive Treatise, 2nd edn. New York: Plenum Press, $1986 ; 174$.
2. Vizmanos B, Martí-Henneberg C, Clivillé R, Moreno A, FernándezBallart J. Age of pubertal onset affects the intensity and duration of pubertal growth peak but not final height. Am J Hum Biol 2001;13: 409-16.

3. Bourguignon JP. Variations in duration of pubertal growth: a mechanism compensating for differences in timing of puberty and minimizing their effects on final height. Belgian Study Group for Paediatric Endocrinology. Acta Paediatr Scand Suppl 1988;347:16-24.

4. Karlberg J, Kwan CW, Gelander L, Albertsson-Wikland K. Pubertal growth assessment. Horm Res 2003;60:Suppl 1:27-35.

5. Tanaka T, Suwa S, Yokoya S, Hibi I. Analysis of linear growth during puberty. Acta Paediatr Scand Suppl 1988;347:25-9.

6. Rogol AD, Roemmich JN, Clark PA. Growth at puberty. J Adolesc Health 2002;31:Suppl 6:192-200.

7. Tanner JM, Whitehouse RH, Marubini E, Resele LF. The adolescent growth spurt of boys and girls of the Harpenden growth study. Ann Hum Biol 1976;3:109-26.

8. Hagg U, Taranger J. Maturation indicators and the pubertal growth spurt. Am J Orthod 1982;82:299-309.

9. Shangold MM, Kelly M, Berkeley AS, Freedman KS, Groshen S. Relationship between menarcheal age and adult height. South Med J 1989;82: 443-5.

10. Onland-Moret NC, Peeters PH, van Gils CH, et al. Age at menarche in relation to adult height: the EPIC study. Am J Epidemiol 2005;162: 623-32.

11. De Simone M, Farello G, Palumbo M, et al. Growth charts, growth velocity and bone development in childhood obesity. Int J Obes Relat Metab Disord 1995;19:851-7.

12. He Q, Karlberg J. Bmi in childhood and its association with height gain, timing of puberty, and final height. Pediatr Res 2001;49:244-51.

13. Bielicki T, Waliszko A. Wrocław growth study part I: females. Stud Phys Anthropol 1975;2:53-83.

14. Waliszko A, Jedlinsska W. Wrocław growth study part II: males. Stud Phys Anthropol 1976;3;27-48.

15. Karlberg J. A biologically-oriented mathematical model (ICP) for human growth. Acta Paediatr Scand Suppl 1989;350:70-94. 